\title{
Assessing the air quality of megacities during the COVID-19 pandemic lockdown: a case study from Makkah City, Saudi Arabia
}

\author{
Essam Morsy ${ }^{1,2,3} \cdot$ Turki M. Habeebullah ${ }^{2} \cdot$ Abdullah Othman $^{1,4}$ \\ Received: 22 December 2020 / Accepted: 4 March 2021 / Published online: 18 March 2021 \\ (C) Saudi Society for Geosciences 2021
}

\begin{abstract}
Many countries are concerned about how concentrations of outdoor air pollutants have decreased due to control measures aftermath of the COVID-19 outbreak. In Saudi Arabia, the measures started with suspending entry to Saudi Arabia on February 27, 2020, and ended with full prevention of Saudis for outdoor movement on April 2, 2020, until the back return to normal life by the start of September 2020. These measures are expected to impact air quality levels during this period by decreasing the concentrations of air pollutants. This paper investigates the major trends of ambient air pollution $\left(\mathrm{SO}_{2}, \mathrm{NO}_{2}, \mathrm{CO}\right.$, $\mathrm{O}_{3}$, and $\mathrm{PM}_{10}$ ), and maps the spatiotemporal variability of air pollutants in Makkah city, using a continuous air quality monitoring network (6 sites) during the pre-pandemic period. Findings indicate the presence of a significant decrease of concentration rates during the lockdown period, compared with the pre-pandemic period, by $26.34 \%$ for $\mathrm{SO}_{2}, 28.99 \%$ for $\mathrm{NO}_{2}, 26.24 \%$ for $\mathrm{CO}$, $11.62 \%$ for $\mathrm{O}_{3}$, and $30.03 \%$ for $\mathrm{PM}_{10}$. Therefore, the vehicular traffic activities represent $25-30 \%$ of the total air pollution load in Makkah city. The COVID-19 lockdown conditions in Makkah provide a unique opportunity to evaluate the impact of the reduction of vehicular traffic activities on the air quality levels of Makkah city and similar mega-cities and introduce credible solutions to improve the conditions of the ambient environment and air quality in such settings.
\end{abstract}

Keywords COVID-19; Air quality $\cdot$ Pollution $\cdot$ Environmental assessment $\cdot$ Traffic $\cdot$ Saudi Arabia

\section{Introduction}

It is particularly important, and valuable from an air quality point of view, to evaluate the background concentrations of air pollutants during the coronavirus COVID-19 pandemic and the associated control measures in the action of nationwide lockdown in Saudi Arabia. Makkah city, which is located in

Responsible Editor: Amjad Kallel

Abdullah Othman

agothman@uqu.edu.sa

1 Natural Hazards Research Unit, Department of Environmental and Health Research, Umm Al-Qura University, Makkah 21955, Saudi Arabia

2 Air Quality, Meteorology and Climate Research Unit, Department of Environmental and Health Research, Umm Al-Qura University, Makkah, Saudi Arabia

3 Department of Geophysics, Faculty of Science, Cairo University, Giza, Egypt

4 Department of Environmental Engineering, Umm Al-Qura University, Makkah, Saudi Arabia the southwest of the Kingdom of Saudi Arabia (KSA), is considered the holiest city in the Muslim world and is a dense-populated city located about $70 \mathrm{~km}$ inland from the Red Sea with millions of Muslims gathered to perform Umrah (fasting month) and pilgrimage (Hajj) every year (Abdou 2014; Munir et al. 2018). KSA exerts tremendous efforts to provide all the required services and to ensure a comforting and sustainable living environment. The atmospheric environment is one of the most critical issues in Makkah, especially during Hajj and Ramadan (fasting month).

More than 10 million Muslims are gathered annually in Makkah to perform Umrah. The Umrah performers are distributed over all the year but densely concentrated during the fasting month of Ramadan in the central part of Makkah city around the Holy Mosque, and Hajj (pilgrimage) performers by about three million are visiting Makkah during the Hajj month (nearly between August and October for the last decade). All these performers of Umrah and Hajj in addition to residents of Makkah contribute to the increasing use of traffic activities that may lead to air pollution (General Authority for Statistics (GAS) 2019). 


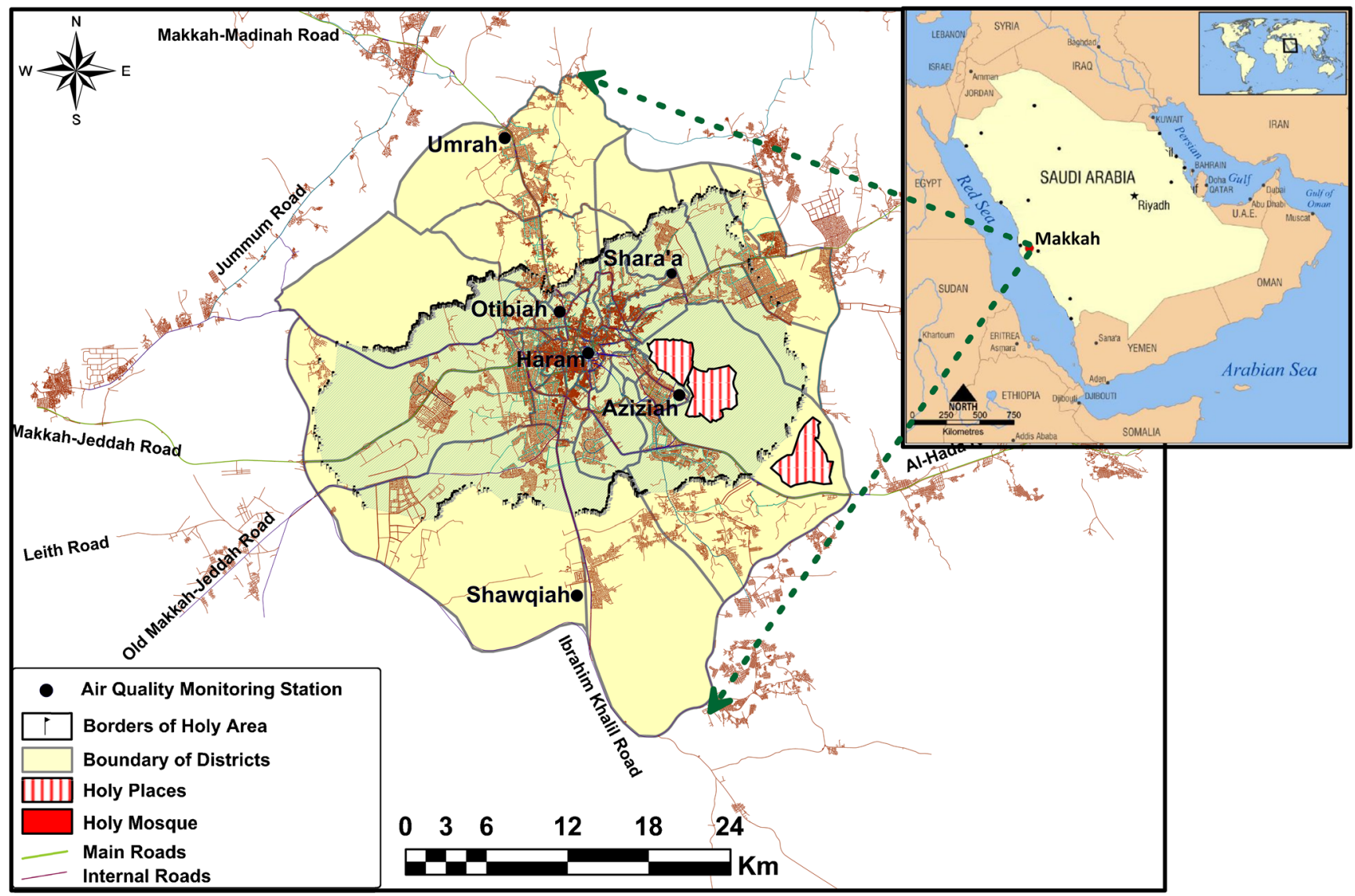

Fig. 1 The location of six air quality monitoring stations in Makkah

Numerous researchers have studied the pollution levels of atmospheric pollutants in Makkah (e.g., Munir et al. 2013a, b; Habeebullah 2013a, b; Seroji 2011; Munir and Habeebullah 2018). However, most of these studied concentrated on the particulate matter concentration (PM10), which is considered the main vital pollutant of concern in Makkah city, in addition to some studies that focused on Ozone $\left(\mathrm{O}_{3}\right)$. Therefore, it is an interesting subject to investigate the background levels of air pollutants during the COVID-19 lockdown (March 11 to August 31, 2020) in Makkah city.
During the COVID-19 outbreak in Saudi Arabia, the first confirmed case was detected on March 2, 2020. In order to control the rapid spread of the COVID-19, the epidemic center, which belong to the Ministry of Health $(\mathrm{MoH})$ in KSA and in Makkah city specifically, more than 1.7 million residents have been placed on effective lockdown on March 23 and the lockdown measures were shortly after implemented in the entire KSA. Holy sites were closed across the nation, public gatherings were cancelled, and people were encouraged to stay at home. All school activities were suspended and were a

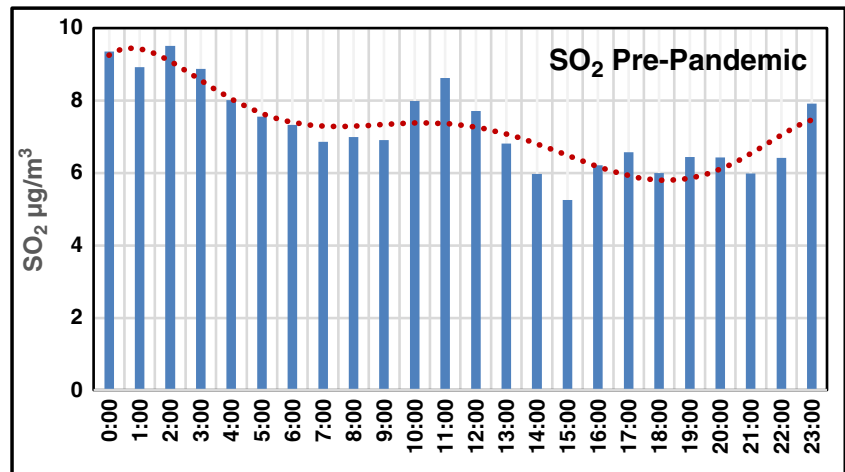

b

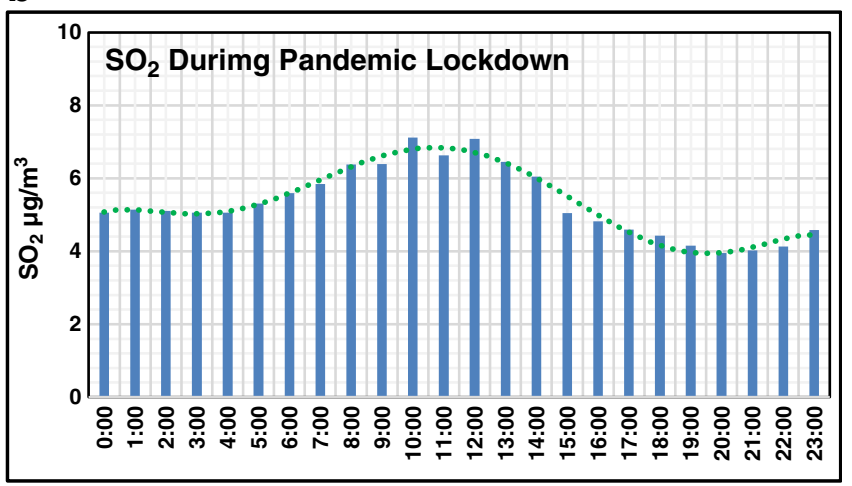

Fig. 2 Diurnal variation of $\mathrm{SO}_{2}$ in Makkah at a pre-pandemic period and $\mathbf{b}$ during pandemic lockdown period 
a

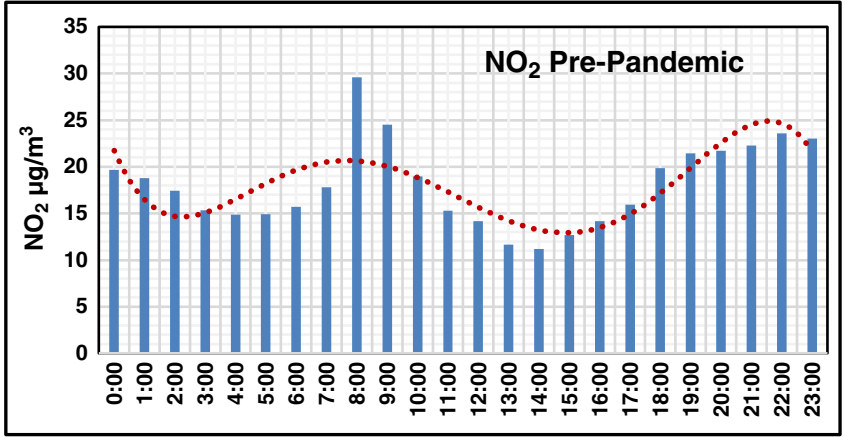

b

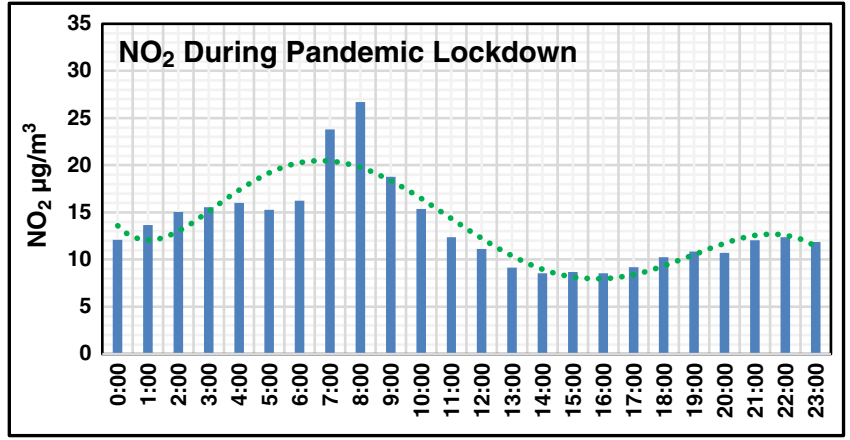

Fig. 3 Diurnal variation of $\mathrm{NO}_{2}$ in Makkah at a pre-pandemic period and $\mathbf{b}$ during pandemic lockdown period

replaced by online teaching platforms. The implementation of lockdown policies has effectively limited inbound and outbound transportation to Makkah except for vital purposes, together with the mobility of people within the entire country has been largely reduced. This has led to a direct impact on the atmospheric environment (MoH 2020).

COVID-19 pandemic has changed the lifestyle completely, due to the exceptional lockdown and the implemented actions including a complete suspension of Holy places, schools, universities, and governmental entities. All these factors encouraged us to investigate the tempo-spatial air quality levels in Makkah to be correlated with the pre-pandemic period (January 1 to March 10, 2020).

The expected enhancement in the levels of air pollutants does not indicate any novelty. Still, the important task is quantifying the rate of decrease in air pollutants levels due to the implemented measures of a sharp reduction in traffic activities and suspending the visitors in the holy places, in addition to all the related issues of public gathering in Makkah, which can be indicative of the limits of measures that can be applied for enhancing the air quality levels in Makkah. The recent research activities that focused on enhancing air pollutants during the COVID-19 lockdown period were related to reducing traffic and industrial activities (Mahato et al. 2020; Tobias et al. 2020; Nakada and Urban 2020; Zambrano-Monserrate et al. 2020; Selvam et al. 2020). These reports indicated the decrease of air pollutants concentrations by $20-60 \%$ in the main cities of Brazil, China, and Spain.

Air contamination that is related to human and traffic activities is a global reality, which leads to several healthassociated problems (Chen et al. 2008; Pope III 2007; Dominici et al. 2006; Brook et al. 2004; Hosseini and Shahbazi 2016; Seifi et al. 2019). The COVID-19 pandemic event makes it possible to determine the pollution levels that may be associated with the traffic component in Makkah that will be a useful issue for the researchers to evaluate the rate of this contamination source, then optimizing the most suitable alternatives and solutions for enhancing air quality in Makkah. This research presents a general overview and the major trend of ambient air pollution and mapping the spatiotemporal variability of air pollutants in Makkah city, using a continuous air quality monitoring network (6 sites) during the pre-pandemic (January 1 to March 10, 2020) and during the COVID-19 pandemic lockdown (March 11 to August 31, 2020), throughout the major air quality indicators $\left(\mathrm{SO}_{2}, \mathrm{NO}_{2}, \mathrm{CO}, \mathrm{O}_{3}\right.$, and $\left.\mathrm{PM}_{10}\right)$ with meteorological parameters (wind speed, wind direction, relative humidity, temperature, and rainfall), in addition to the average rate of decrease of ambient air quality parameters in Makkah resulting from COVID-19 lockdown. a

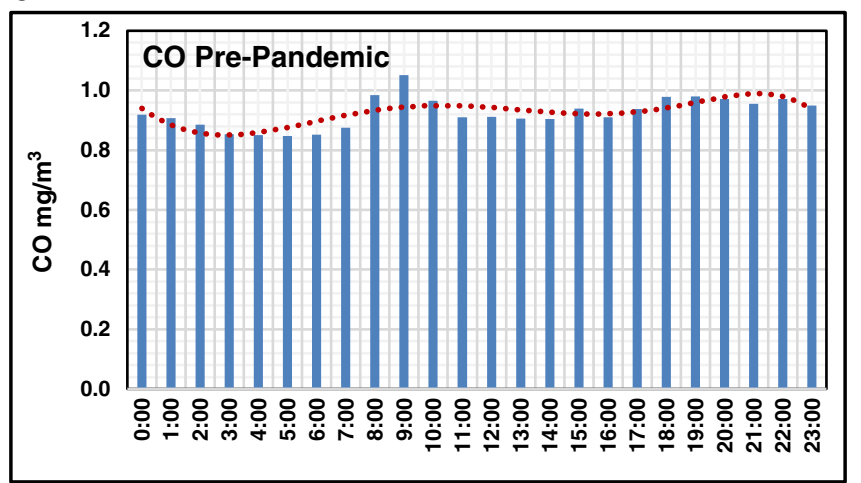

b

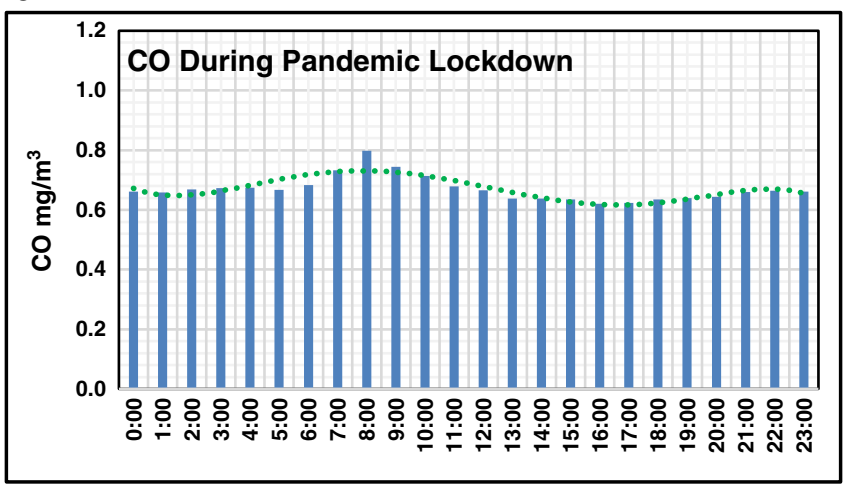

Fig. 4 Diurnal variation of CO in Makkah at a pre-pandemic period and $\mathbf{b}$ during pandemic lockdown period 
a

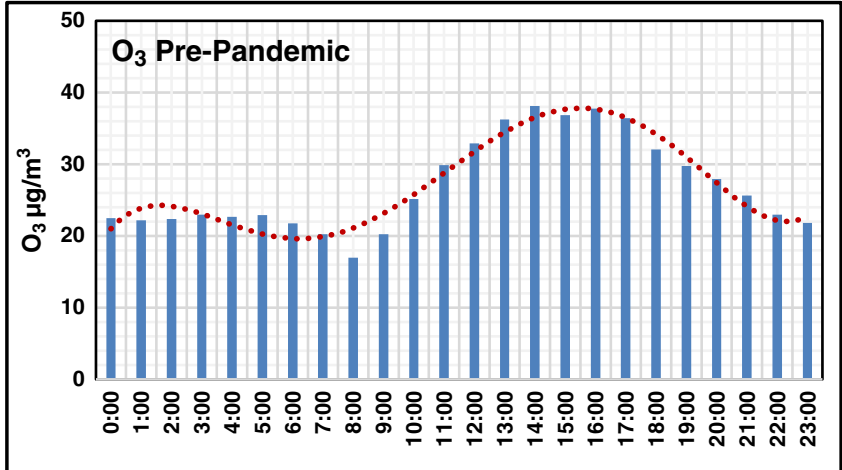

b

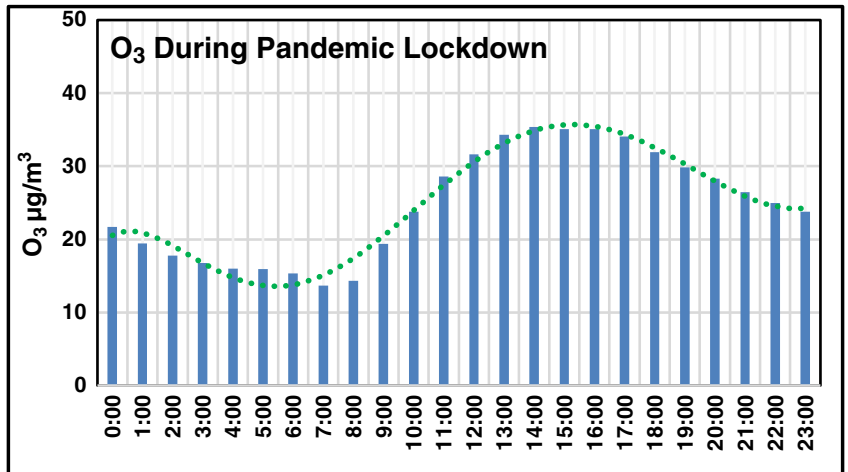

Fig. 5 Diurnal variation of $\mathrm{O}_{3}$ in Makkah at a pre-pandemic period and $\mathbf{b}$ during pandemic lockdown period

\section{Materials and methods}

Makkah is situated within the southern part of the Hijaz region on the west-central part of the Arabian Shield, mainly composed of different types of igneous, metamorphic, and sedimentary rocks of Precambrian and lower Paleozoic age (Greenwood et al. 1976). In addition, there are subordinate sedimentary rocks and basaltic lava flow of Tertiary and Quaternary age (Sonbbl 1995). Topographically, Makkah has been subject to continuous uplift since the Red Sea rifting during the Oligocene time, leading to rough terrain with a varying topography between 300 and $980 \mathrm{~m}$ concerning sea level. The ranges of mountains in Makkah are controlled by the Red Sea dominant geological structural elements (Abotalib et al. 2019; Othman and Abotalib 2019) with dominant northwest-southeast (e.g., Mena Mountains) and east-west trends (e.g., El Tarqi Mountains). However, few mountains are isolated and conform semi-circular shape such as Thawr Mountain (755 m) and El Nour Mountain (642 m) (El Bastawesy et al. 2012; Othman et al. 2020).

Globally, networks of air quality monitoring stations can be utilized on the local, national, and worldwide scales (Elkadiri et al. 2016), due to the cumulative observations of the collected data on long-term periods: (a) a full understanding of dominant trends of pollution on the studied sites, (b) evaluation of the abrupt episodes of air pollution, (c) informing the public

a

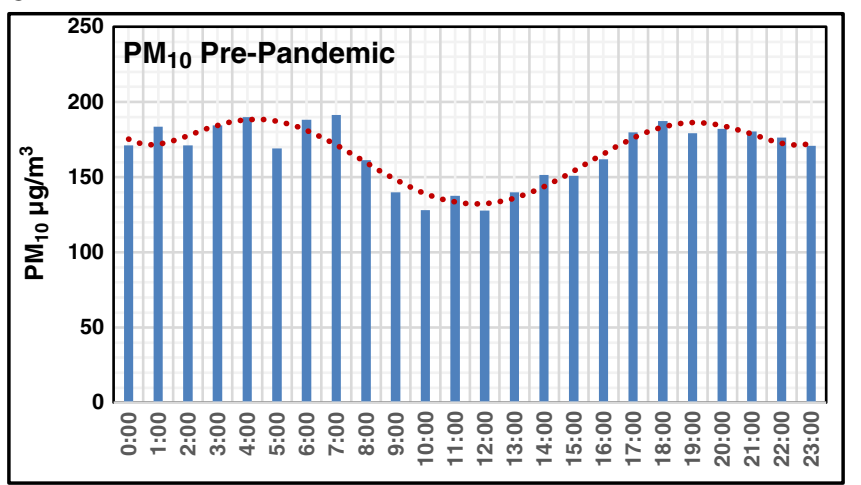

by the levels of local air quality, and (d) providing the decision-makers and policymakers with the accumulated levels of air quality to optimize the most compatible strategies for controlling the pollution levels (Cyrys et al. 2012).

Instrumentation and analytical methodologies of air quality analyzers vary depending on the detection and trace species techniques: $\mathrm{NO}$ and $\mathrm{NO}_{2}$ (APNA370: chemiluminescence,); $\mathrm{O}_{3}$ (APOA370: UV photometric); $\mathrm{SO}_{2}$ (APSA370: UV fluorescence); CO (APMA370: IR Absorption); $\mathrm{PM}_{10}$ (BAM1020: bray). Controlling the quality and assurance of air quality data was based on the standard operation procedure (SOP) published by PME.

In the current research, the utilized air quality data were derived from a total of six fixed continuous air quality monitoring stations (AQMS), which belong to the Presidency of Meteorology and Environment (PME). These AQMS stations are distributed in Makkah city to cover the most dominant activities such as (1) Haram AQMS $(21.42464,39.82917)$ that located in the eastern yard of the Holy Mosque and representing the traffic and visitors activities, (2) Taneem AQNS $(21.50847,39.79339)$ situated on the northwest of Makkah city which represents the industrial activities and the already-existing power plants; (3) Otebiah AQMS (21.44222, 39.81189), which is located around Holy Mosque and represent the mixed activities of traffic and

b

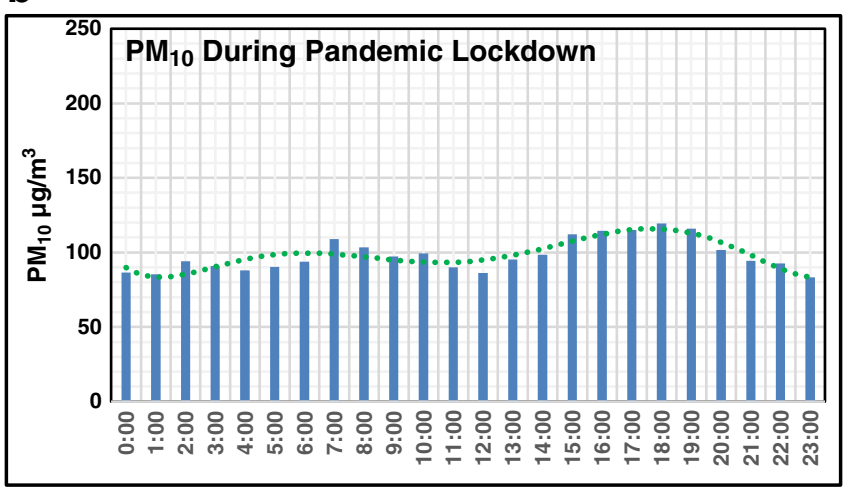

Fig. 6 Diurnal variation of $\mathrm{PM}_{10}$ in Makkah at a pre-pandemic period and $\mathbf{b}$ during pandemic lockdown period 
a

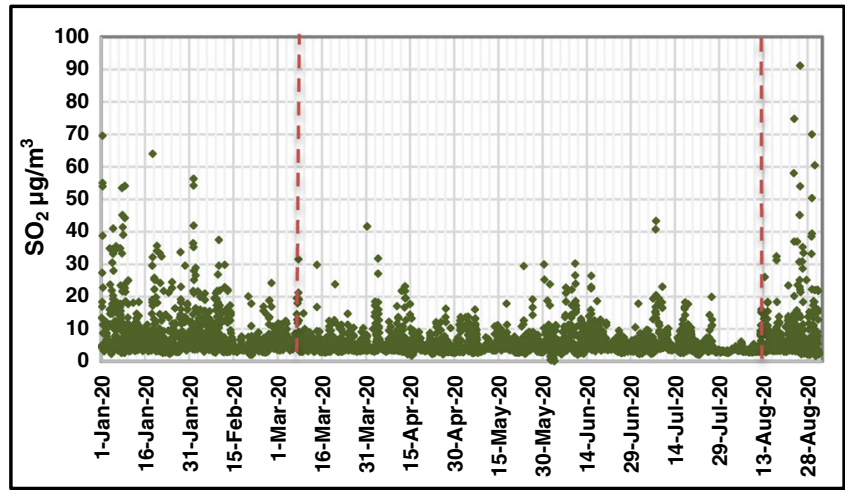

Fig. 7 Concentration of $\mathrm{SO}_{2}$ at Makkah a hourly average, $\mathbf{b}$ daily average

housing; (4) Shawqia AQMS (21.36589, 39.80747) situated southwest of Makkah and equivalent to residential activities; (5) Aziziah AQMS (21.40377, 39.87837) located close to Holy Mosque and contains a large number of hotels; and (6) Shara'a AQMS (21.46472, 39.93919), which represents a major residential area and is located in the east of Makkah (Fig. 1).

The statistical treatment of air quality data through the current study using the Microsoft Excel and the "Grapher" software packages was utilized to investigate the temporal variations and the "SURFER" packages was applied to represent the spatial variations of the air quality data in the form of contour maps.

The average percent reduction of ambient air quality parameters in Makkah as a result of COVID-19 lockdown was computed using the following equation:

$\mathrm{APR}=\left(\left(\mathrm{DAQP}_{\text {Jan-10 Mar }}-\mathrm{DAQP}_{11}\right.\right.$ Mar-31 A Augast $\left.) / \mathrm{DAQP}_{\text {Jan-10 Mar. }}\right) \times 100$

where

APRaverage percent reduction of air quality parameter,

$\mathrm{DAQP}_{1 \mathrm{Jan}-10}$ Mar.daily average of air quality parameter during pre-pandemic period (January 1 to March 10, 2020), and

a

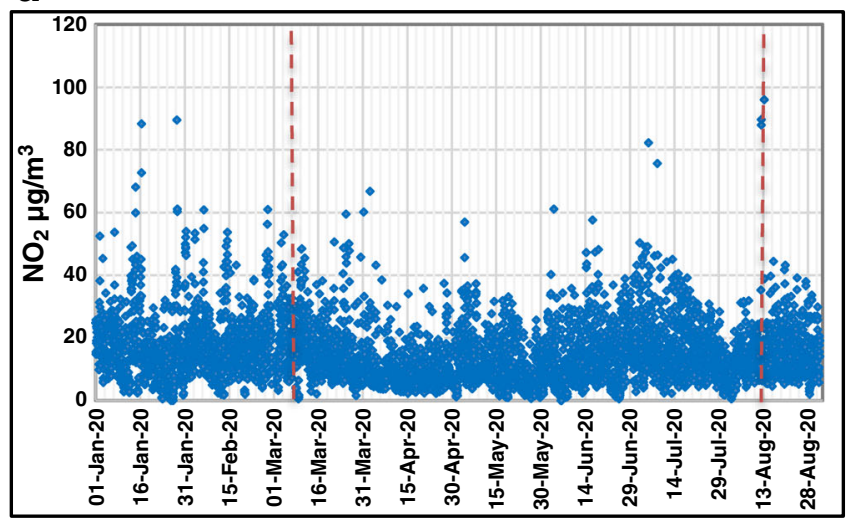

b

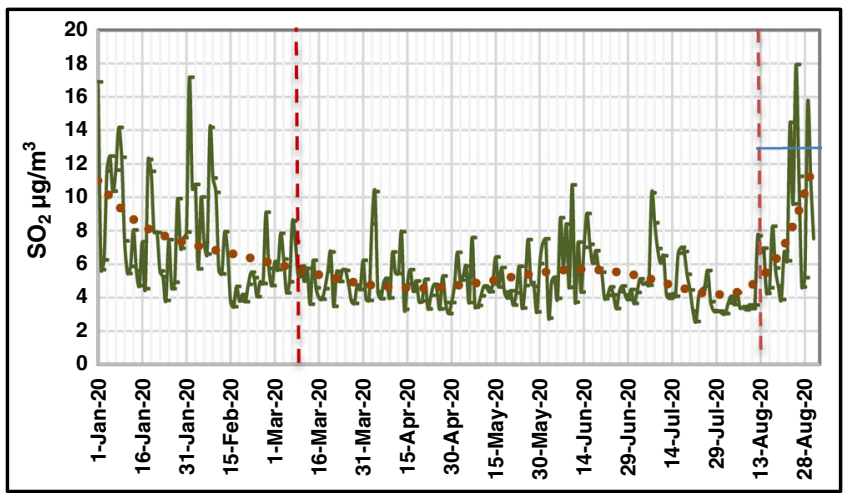

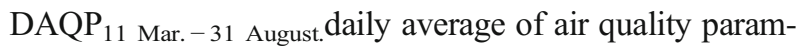
eter during pandemic period (March 11 to August 31, 2020).

\section{Results and discussion}

\section{Overview and major trend of air pollution concentrations in Makkah}

In Makkah, it is interesting to indicate that the daily pattern (diurnal variation) of $\mathrm{SO}_{2}$ concentration in our study is exactly similar to day-to-day variations of vehicular traffic activities. The morning peak is only likely due to vehicular traffic in the morning (10:00 and 11:00), whereas another peak can be related to the traffic of light-duty vehicles in the late afternoon and early evening accompanied by increasing heavy-duty vehicle-related traffic during night-time (after 23:00) as a traffic restriction, construction/ demolition activities, and their related-waste transfer and management, open burning of solid waste, switching of the air pollution control equipment at night (Fig. 2a), whereas during the pandemic lockdown period (March 11 to August 31, 2020), the peaks are not well marked that can be interpreted by the commitment of Makkah residents to the precautionary measures of COVID-19 (Fig. 2b).

b

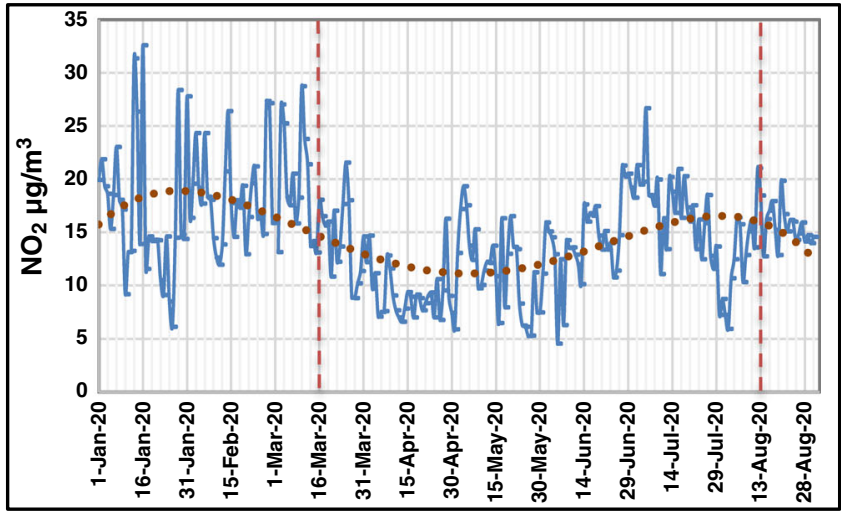

Fig. 8 Concentration of $\mathrm{NO}_{2}$ at Makkah a hourly average, $\mathbf{b}$ daily average 
a

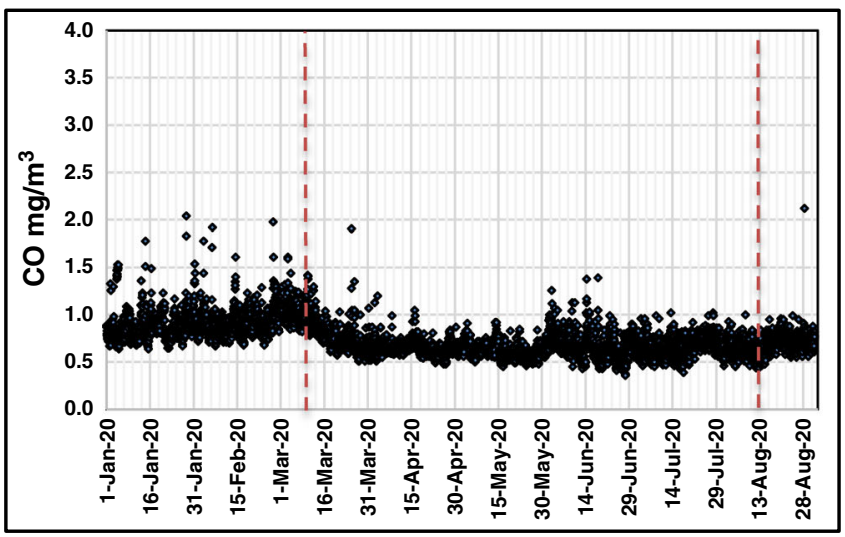

Fig. 9 Concentration of $\mathrm{CO}$ at Makkah a hourly average, $\mathbf{b}$ daily average

a

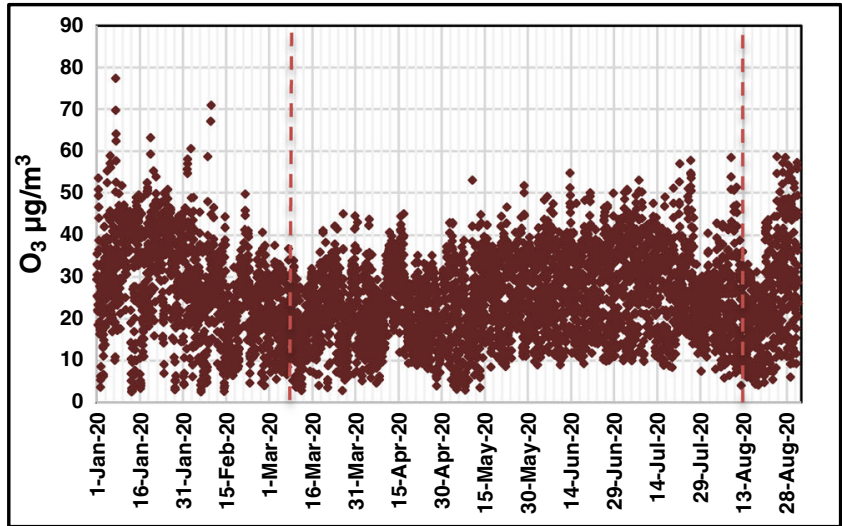

Fig. 10 Concentration of $\mathrm{O}_{3}$ at Makkah a hourly average, $\mathbf{b}$ daily average

Similar to ambient diurnal variation of $\mathrm{SO}_{2}$ concentration in Makkah on pre-pandemic conditions (January 1 to March 10, 2020), $\mathrm{NO}_{2}$, and $\mathrm{CO}$ hourly diurnal variation are clearly exhibited two peaks and two troughs, mainly reflecting the effect of traffic emissions and meteorological conditions (Figs. 3 and 4). After the observed peaks at 7:00 and 8:00, the concentrations of $\mathrm{NO}_{2}$, and $\mathrm{CO}$ started to decrease and reached their lowest

a

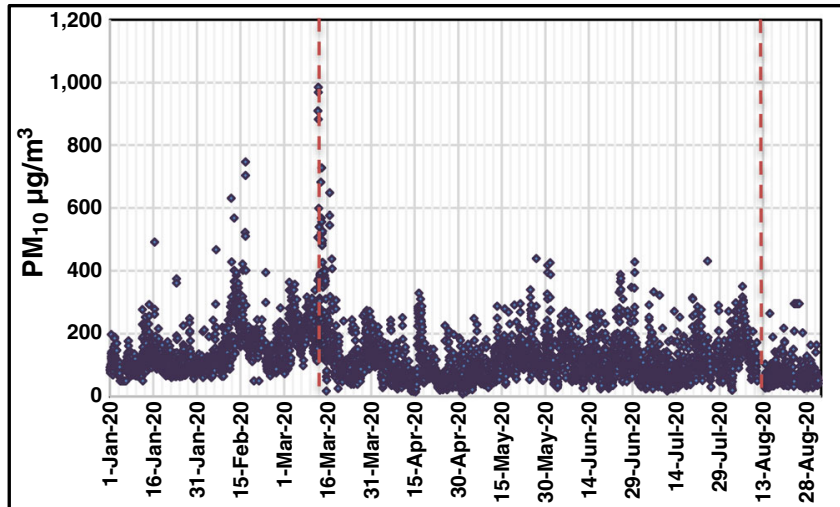

b

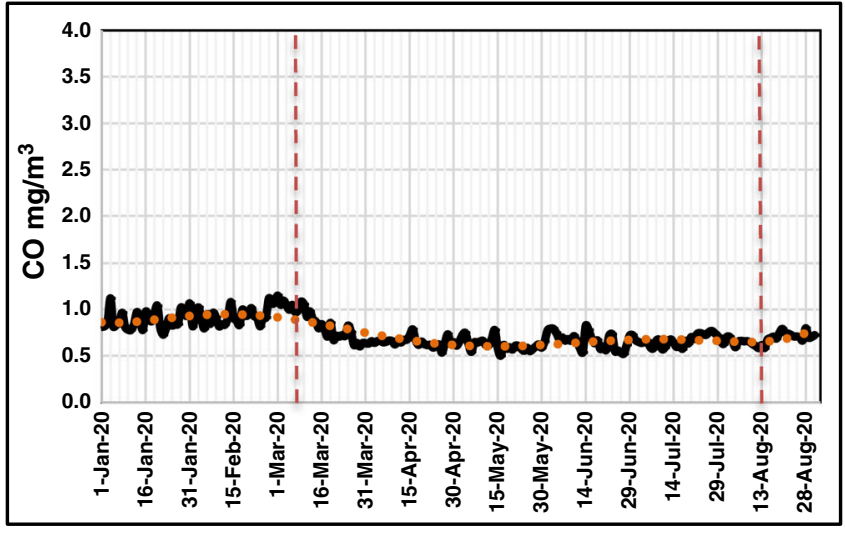

b

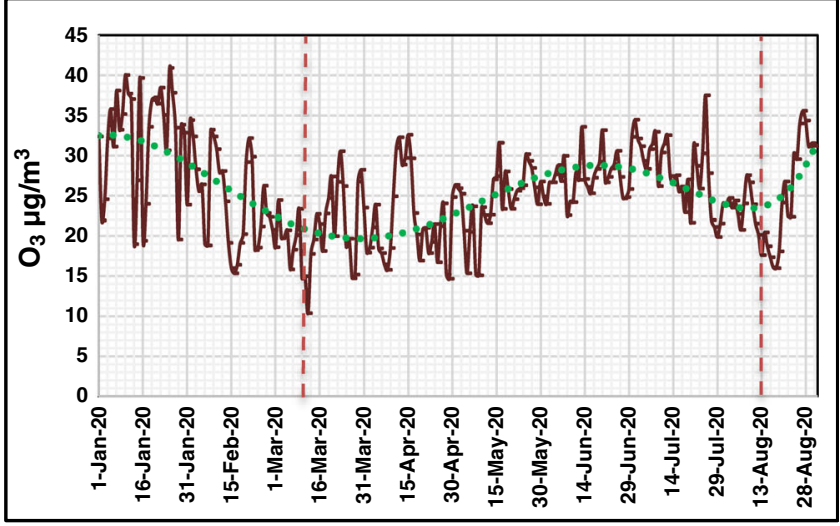

concentrations at 14:00 and 15:00 due to a combination of increasing boundary layer height, wind speed (WS), solar radiation (SR), and photochemical reactions in order to produce $\mathrm{O}_{3}$ coupled with decreasing vehicle traffic emissions as evident by decreased ambient $\mathrm{NO}_{2}$. The night-time concentrations of $\mathrm{NO}_{2}$ and $\mathrm{CO}$ were significantly lower than those observed during the daytime, mainly because of the above-mentioned reasons, as well

b

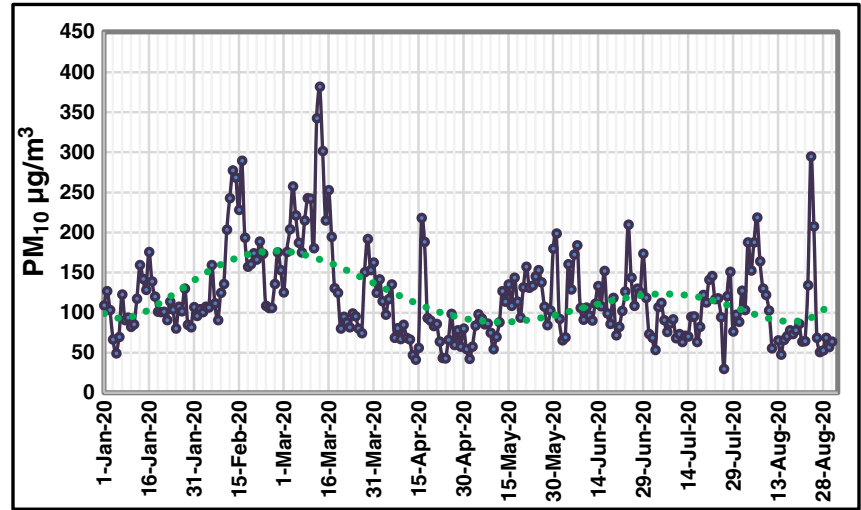

Fig. 11 Concentration of $\mathrm{PM}_{10}$ at Makkah a hourly average, $\mathbf{b}$ daily average 

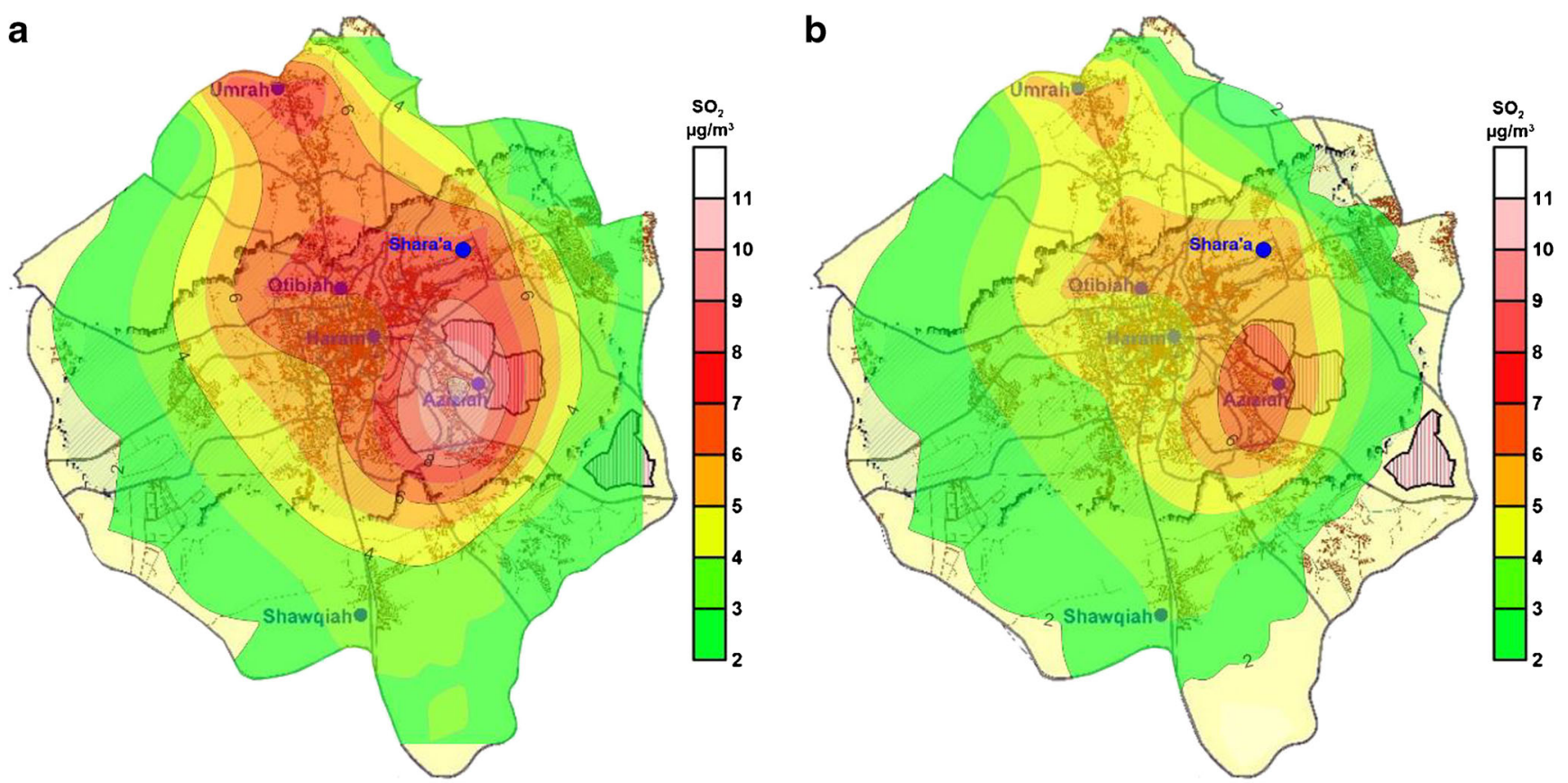

Fig. 12 Contour map of daily average $\mathrm{SO}_{2}$ concentration in Makkah at a pre-pandemic period and $\mathbf{b}$ during pandemic period

as the lack of photochemical reactions for their destruction and consumption to produce ambient $\mathrm{O}_{3}$ (Hu et al. 2014; Heger and Sarraf 2018; Taghvaee et al. 2018a, b; Henschel et al. 2015; Askariyeh and Arhami 2013; Song et al. 2017; Ezimand and Kakroodi 2019; Zuberi et al. 2015).

Furthermore, diurnal variation of $\mathrm{O}_{3}$ revealed a sharp mountain-peak-shaped pattern after midday (15:00 and 16:00) owing to higher SR and photochemical reactions in the early afternoon (Fig. 5). Unlike other air pollutants, $\mathrm{SO}_{2}$ revealed no specific hourly pattern, though its hourly variation and its concentration was statistically significant in the vast majority of hours. $\mathrm{O}_{3}$ formation was also affected by solar radiation's intensity (MEE 2016, 2017 and 2018; Henschel et al. 2015; Tonse et al. 2008).

According to the diurnal variation of $\mathrm{PM}_{10}$, two peaks were observed; one in the morning (07:00) and another in the night (18:00) (Fig. 6a), with concentrations of 191.3 and $187.3 \mu \mathrm{g} /$ $\mathrm{m}^{3}$ respectively during the pre-pandemic. Moreover, as shown
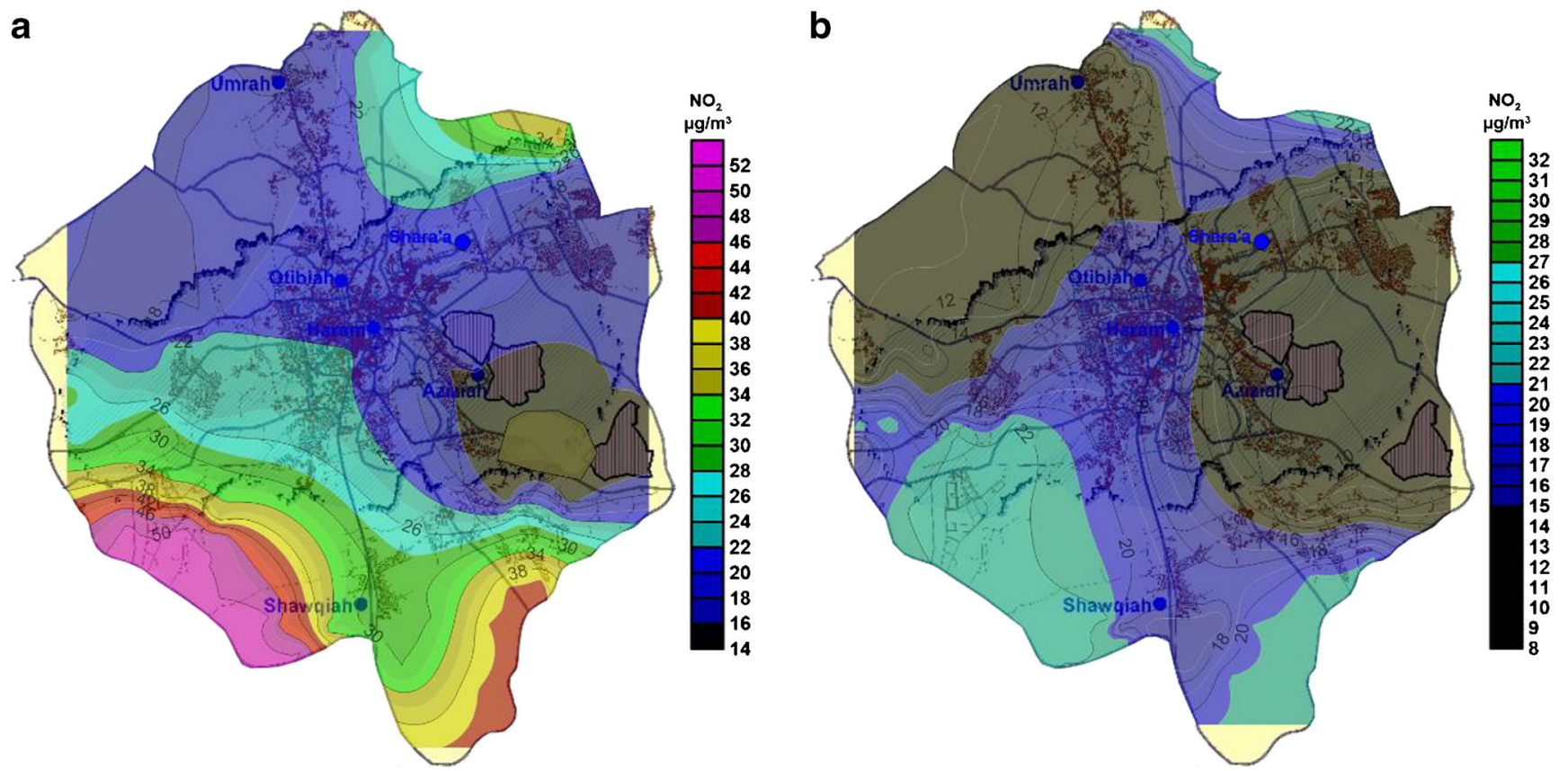

Fig. 13 Contour map of daily average $\mathrm{NO}_{2}$ concentration in Makkah at a pre-pandemic period and $\mathbf{b}$ during pandemic period 

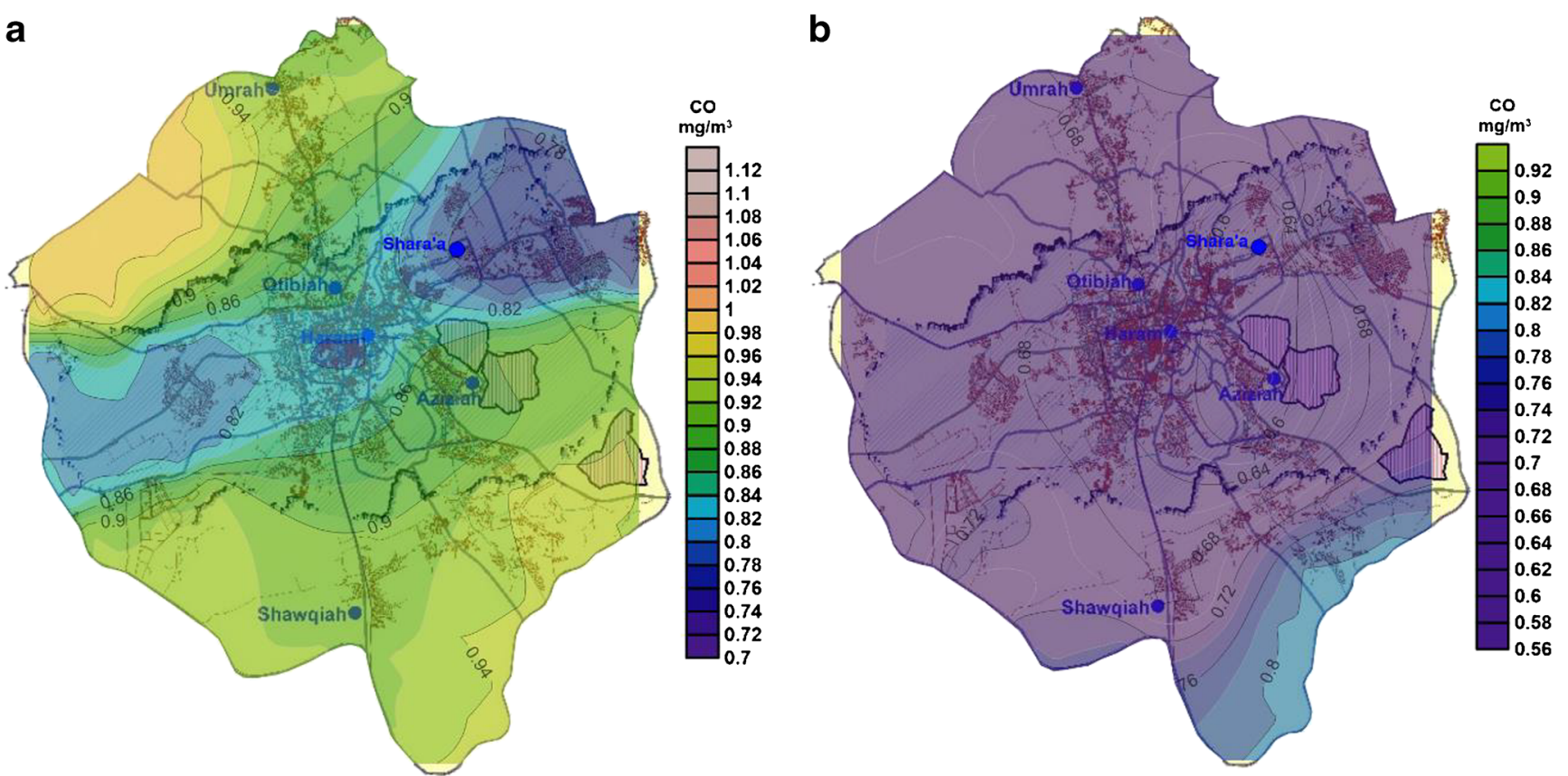

Fig. 14 Contour map of daily average $\mathrm{CO}$ concentration in Makkah at a pre-pandemic period and $\mathbf{b}$ during pandemic period

in Fig. 6b, the $\mathrm{PM}_{10}$ concentrations were flat throughout the daytime during the pandemic lockdown period (March 11 to August 31,2020 ) and the peaks are not well marked that can be interpreted by commitment of Makkah residents to the precautionary measures of COVID-19. It is worth noting that hourly patterns of $\mathrm{PM}_{10}$ are commonly used as a notable marker of combustion emissions from road traffic and traffic-related emissions and meteorological conditions (Geng et al. 2015; Xu et al. 2016; Faridi et al. 2018;
Taghvaee et al. 2018a, b; Squizzato et al. 2018; AlizadehChoobari et al. 2016; Ahmed et al. 2015; Hu et al. 2014).

\section{Temporal variation of air pollutants in Makkah}

By correlating the hourly average concentrations of five criteria of air pollutants in Makkah for the six AQMS distributed all-over Makkah, during the emphasized period from January 1 to August 31,2020 , the hourly average
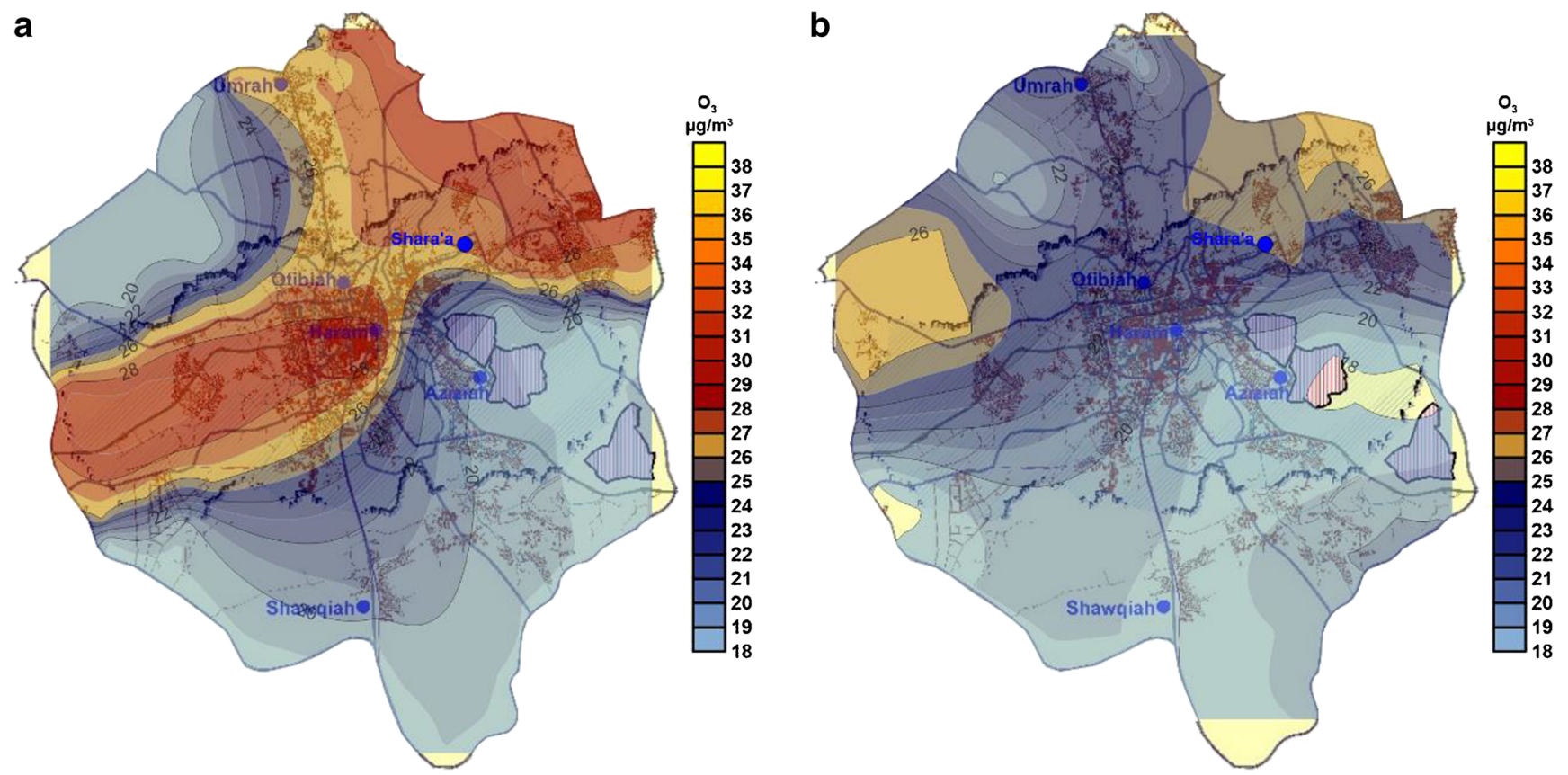

Fig. 15 Contour map of daily average $\mathrm{O}_{3}$ concentration in Makkah at a pre-pandemic period and $\mathbf{b}$ during pandemic period 

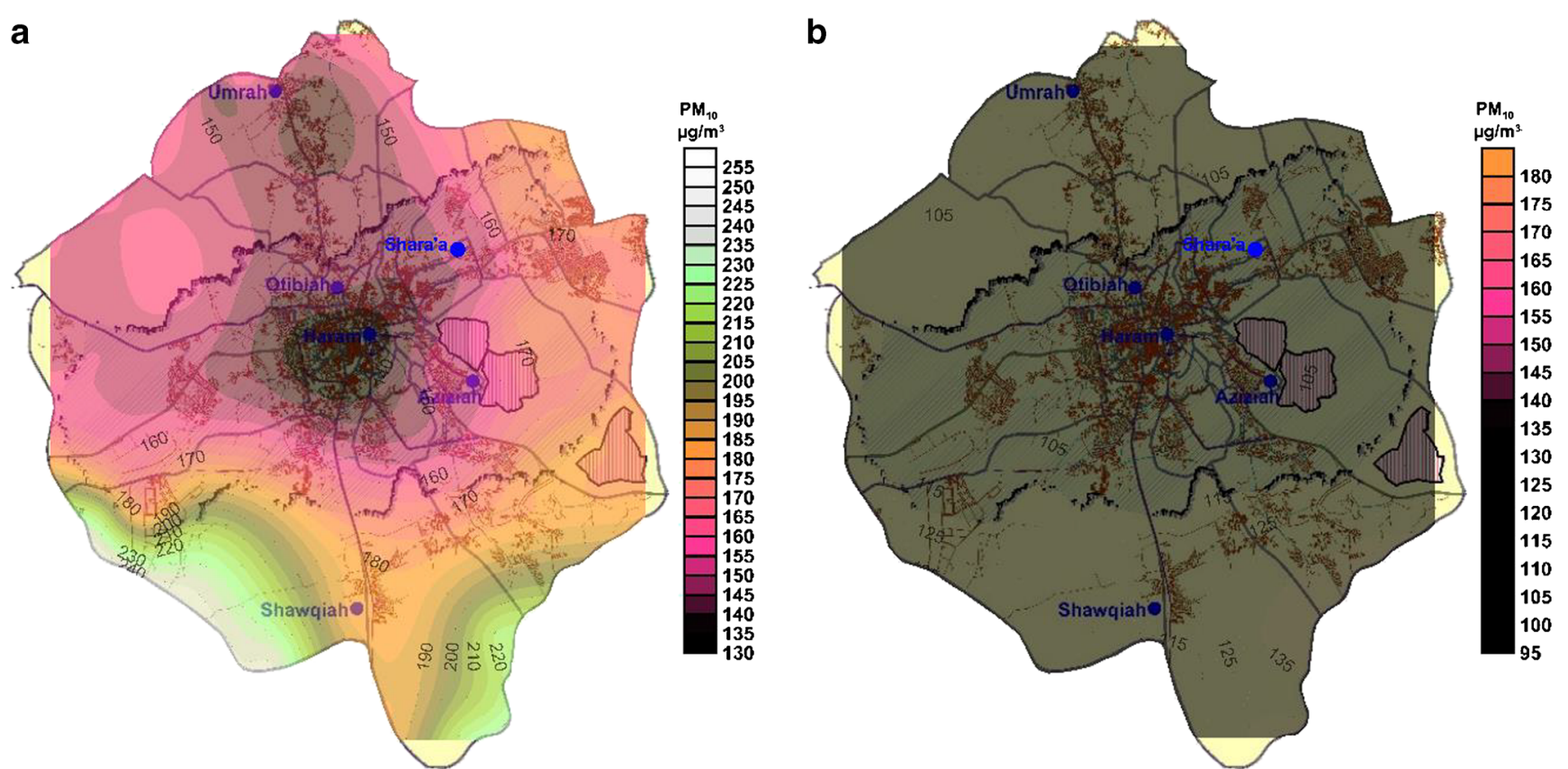

Fig. 16 Contour map of daily average $\mathrm{PM}_{10}$ concentration in Makkah at a pre-pandemic period and $\mathbf{b}$ during pandemic period

concentration for $\mathrm{SO}_{2}, \mathrm{NO}_{2}, \mathrm{CO}, \mathrm{O}_{3}$, and $\mathrm{PM}_{10}$ was registered during the pre-pandemic period (January1 to March 10, 2020) as mean for all six AQMS stations with approximately 7.27, $18.10,0.93,26.98$, and $142.0 \mu \mathrm{g} / \mathrm{m}^{3}$ respectively, whereas the daily average concentration of $\mathrm{SO}_{2}\left(7.22 \mu \mathrm{g} / \mathrm{m}^{3}\right), \mathrm{NO}_{2}(18.13$ $\left.\mu \mathrm{g} / \mathrm{m}^{3}\right), \mathrm{CO}\left(0.93 \mathrm{mg} / \mathrm{m}^{3}\right), \mathrm{O}_{3}\left(26.76 \mu \mathrm{g} / \mathrm{m}^{3}\right)$, and $\mathrm{PM}_{10}(143$ $\mu \mathrm{g} / \mathrm{m}^{3}$ ) (Figs. 7, 8, 9, 10, and 11), while during the period from March 11 to August 31, 2020 (that equivalent to COVID-19 lockdown), the hourly average concentration for $\mathrm{SO}_{2}, \mathrm{NO}_{2}, \mathrm{CO}, \mathrm{O}_{3}$, and $\mathrm{PM}_{10}$ was registered as mean for all six AQMS stations with approximately 5.31, 13.48, 0.67, 24.77 , and $112.0 \mu \mathrm{g} / \mathrm{m}^{3}$ respectively, whereas the daily average concentration of $\mathrm{SO}_{2}\left(5.31 \mu \mathrm{g} / \mathrm{m}^{3}\right), \mathrm{NO}_{2}\left(13.38 \mu \mathrm{g} / \mathrm{m}^{3}\right)$, $\mathrm{CO}\left(0.67 \mathrm{mg} / \mathrm{m}^{3}\right), \mathrm{O}_{3}\left(24.90 \mu \mathrm{g} / \mathrm{m}^{3}\right)$, and $\mathrm{PM}_{10}\left(111 \mu \mathrm{g} / \mathrm{m}^{3}\right)$ (Figs. 7, 8, 9, 10, and 11).

The average hourly concentration of $\mathrm{SO} 2, \mathrm{NO} 2, \mathrm{CO}, \mathrm{O} 3$, and PM10 was lower than the PME (General Presidency of Meteorology and Environment) air quality guidelines during the entire study period. Hourly average concentrations of all ambient air quality parameters were investigated during the period January1 to August 31, 2020. Ambient $\mathrm{SO}_{2}, \mathrm{NO}_{2}, \mathrm{CO}$, $\mathrm{O}_{3}$, and $\mathrm{PM}_{10}$ revealed out significantly higher mean concentrations during COVID-19 pre-pandemic period (January 1 to March 10,2020) according to the implemented precautionary actions of Saudi government (MoH 2020) compared with the COVID-19 pandemic period (March 11 to August 31, 2020), in all the six AQMS in Makkah (Figs. 7, 8, 9, 10, and 11).

\section{Spatial variation of air pollutants}

For studying the spatial variation of ambient air pollutants in Makkah on pre-pandemic and during the pandemic lockdown, a total of ten contour maps were constructed to follow-up the dispersion of pollutants and the most general trend of pollutants in Makkah.
Fig. 17 Comparison between average rates of percent reduction of ambient air pollutants in Makkah between pre-pandemic and during pandemic periods (all parameters in $\mu \mathrm{g} / \mathrm{m}^{3}$ except $\mathrm{CO}$ in $\mathrm{mg} / \mathrm{m}^{3}$ )

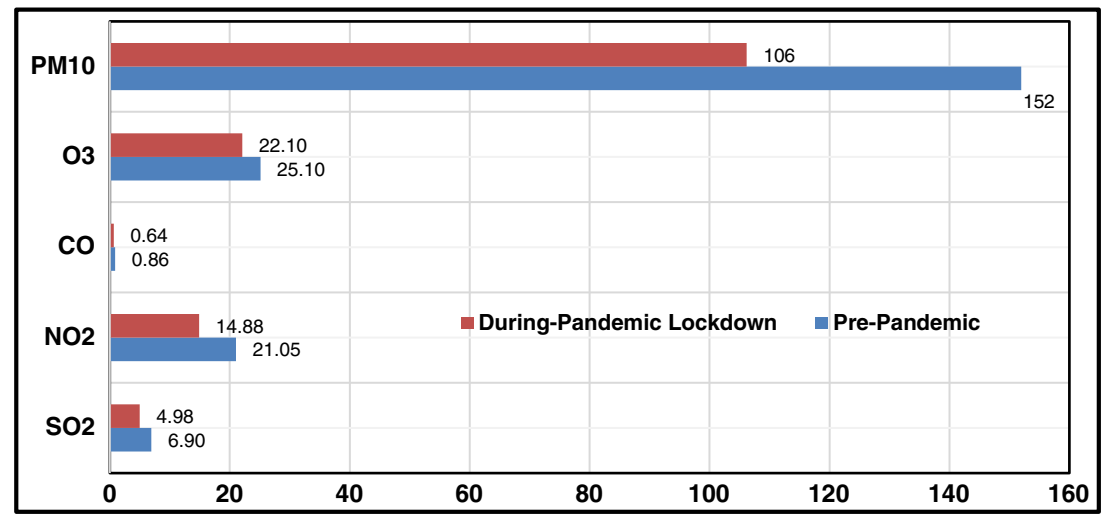


Fig. 18 Average rates of percent reduction of ambient air pollutants in Makkah during pandemic compared with prepandemic period (all parameters in $\mu \mathrm{g} / \mathrm{m}^{3}$ except $\mathrm{CO}$ in $\mathrm{mg} / \mathrm{m}^{3}$ )

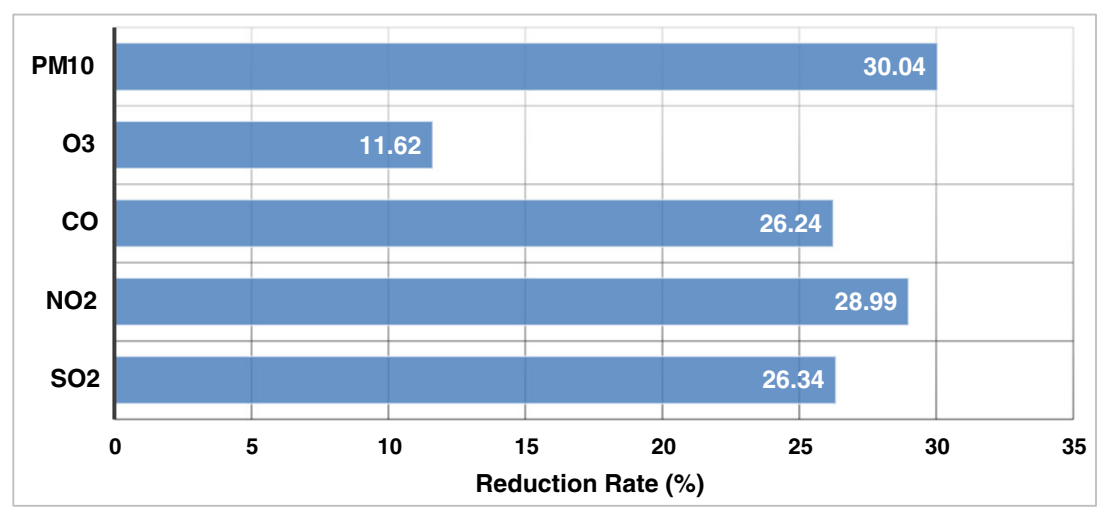

The concentration of $\mathrm{SO}_{2}$ on the pre-pandemic period (January 1 to March 10, 2020) was averaged for all six AQMS distributed in the districts of Makkah; then, the data were coordinated by utilizing "SURFER" software packages, and contoured to show the spatial variation of $\mathrm{SO}_{2}$ in Makkah, which was between 3.5 and $10 \mu \mathrm{g} / \mathrm{m}^{3}$. The low concentrations of $3.5-5.5 \mu \mathrm{g} / \mathrm{m}^{3}$ were presented in the southwest (Shawqia) part, while the high concentrations were focused on the eastern part with a range of $8-10 \mu \mathrm{g} / \mathrm{m}^{3}$, and all the rest of Makkah stations were featured by moderate concentrations between 5 and 7.5 $\mu \mathrm{g} / \mathrm{m}^{3}$ (Fig. 12a), while during the lockdown of the COVID-19 pandemic period (March 11 to August 31, 2020) (Fig. 12b), the concentrations of $\mathrm{SO}_{2}$ have been in the range of $3.0-6.6 \mu \mathrm{g} / \mathrm{m}^{3}$; also, the southwestern part indicated very low concentrations. It is well observed that the decrease of $\mathrm{SO}_{2}$ between the two previously mentioned periods is a direct response to the suspension of all trucks and huge vehicles through the lockdown period in Makkah, in addition to the suspension of Hajj and Umrah with the associated traffic effects.

A similar way of spatial variation of $\mathrm{SO}_{2}$ was designed for the two periods (pre and during the pandemic) for the ambient air pollutants $\mathrm{NO}_{2}, \mathrm{CO}, \mathrm{O}_{3}$, and $\mathrm{PM}_{10} . \mathrm{NO}_{2}$ values ranged between 16 and $30 \mu \mathrm{g} / \mathrm{m}^{3}$ and the maximum concentrations were found in the southwestern part of Makkah during the pre-pandemic periods that ranged between 26 and $30 \mu \mathrm{g} / \mathrm{m}^{3}$, and the lowest concentrations were represented in the eastern and northern parts of Makkah (Fig. 13a), while during the lockdown during the COVID-19 pandemic period (March 11 to August $31,2020)$ (Fig. 13b), there was an abrupt decrease of range of $\mathrm{NO}_{2}$ concentrations between 10 and $19 \mu \mathrm{g} / \mathrm{m}^{3}$. Similarly, the behavior of the $\mathrm{SO}_{2}$ and $\mathrm{NO}_{2}, \mathrm{CO}, \mathrm{O}_{3}$, and $\mathrm{PM}_{10}$ was marked by different ranges of concentrations of $0.71-0.93 \mathrm{mg} / \mathrm{m}^{3} ; 20.0-28.0 \mu \mathrm{g} / \mathrm{m}^{3}$, and $0.57-0.73 \mathrm{mg} /$ $\mathrm{m}^{3} ; 18.0-26.0 \mu \mathrm{g} / \mathrm{m}^{3} ; 143.0-111.0 \mu \mathrm{g} / \mathrm{m}^{3}$, respectively, during the periods of pre-pandemic and pandemic lockdown (Figs. 14a, b, 15a, b and 16a, b).

\section{Quantifying percent reduction of air quality during COVID-19 lockdown}

To quantify the impact of the suspended activities due to the impact of COVID-19 on the air pollutants in Makkah, the hourly averages of the five main pollutants $\left(\mathrm{SO}_{2}, \mathrm{NO}_{2}, \mathrm{CO}\right.$, $\mathrm{O}_{3}$ and $\mathrm{PM}_{10}$ ) were utilized for providing the daily averages; then, the mean concentrations were evaluated for the two periods (pre-pandemic and during the pandemic lockdown) as illustrated in Fig. 17; $\mathrm{SO}_{2}$ has been decreased from 7.28 to $5.31 \mu \mathrm{g} / \mathrm{m}^{3}, \mathrm{NO}_{2}$ has been reduced from 18.11 to $13.48 \mu \mathrm{g} /$ $\mathrm{m}^{3}$, CO has been reduced from 0.93 to $0.67 \mathrm{mg} / \mathrm{m}^{3}, \mathrm{O}_{3}$ has been decreased from 26.99 to $24.76 \mu \mathrm{g} / \mathrm{m}^{3}$, and $\mathrm{PM}_{10}$ has been reduced from 26.99 to $24.76 \mu \mathrm{g} / \mathrm{m}^{3}$.

By application of Equation (1), the rates of percent reduction of ambient air pollutants $\left(\mathrm{SO}_{2}, \mathrm{NO}_{2}, \mathrm{CO}, \mathrm{O}_{3}\right.$, and $\left.\mathrm{PM}_{10}\right)$ for the six AQMS (Haram; Umrah; Otebiah; Shawqia; Aziziah; and Shara'a) in Makkah were estimated and averaged to indicate the average concentration of $\mathrm{SO}_{2}$ decreased by a rate of $26.34 \%, \mathrm{NO}_{2}$ by a rate $28.99 \%, \mathrm{CO}$ by a rate of $26.24 \%, \mathrm{O}_{3}$ by a rate of $11.62 \%$, and $\mathrm{PM}_{10}$ by a rate of $30.04 \%$ (Fig. 18).

\section{Conclusions and recommendations}

The ambient air quality data from six AQMS stations in Makkah City, KSA for min five pollutants including $\left(\mathrm{SO}_{2}\right.$, $\mathrm{NO}_{2}, \mathrm{CO}, \mathrm{O}_{3}$, and $\mathrm{PM}_{10}$ ) were recorded continuously on hourly average basis, in addition to meteorological conditions (atmospheric temperature, relative humidity, atmospheric pressure, wind speed, and wind direction). The main objective of the current research was to investigate and analyze the impact of COVID-19 lockdown on air quality in the different districts of Makkah.

Findings showed that since the control measures adapted by the Saudi government during COVID-19 crisis at the start of March 2020, levels of air pollutants have been greatly lowered. The hourly average, daily averages, and diurnal 
variations confirmed the significant improvement of levels of air pollutants throughout the distributed AQMS all-over Makkah. The hourly averages for the main pollutants of $\mathrm{SO}_{2}, \mathrm{NO}_{2}, \mathrm{CO}, \mathrm{O}_{3}$, and $\mathrm{PM}_{10}$ indicated a decrease from 7.27 to $5.31 \mu \mathrm{g} / \mathrm{m}^{3}, 18.10$ to $13.48 \mu \mathrm{g} / \mathrm{m}^{3}, 0.93$ to $0.67 \mathrm{mg} /$ $\mathrm{m}^{3}, 26.76$ to $24.77 \mu \mathrm{g} / \mathrm{m}^{3}$, and 143.0 to $111 \mu \mathrm{g} / \mathrm{m}^{3}$, respectively, between the pre-pandemic and pandemic periods.

These results indicated that the vehicular traffic activities represent about $25-30 \%$ of the total air pollution load in Makkah city, in addition to the anthropogenic factors that were mainly responsible for the variations in air quality. Further analysis suggested that source apportionment must be conducted especially for $\mathrm{PM}_{10}$, which is the main factor influencing air quality. This research work provides a new view for a comprehensive understanding of the current state of air pollution in Makkah. The findings will provide a theoretical basis for the formulation of future air-pollution control policies in Makkah.

All the ambient air pollutants exhibit a decreasing trend in 2020 compared with 2019. The calculation of the average decrease rate of the five air quality parameters indicated that the average concentration of $\mathrm{SO}_{2}$ decreased by a rate of $26.34 \%, \mathrm{NO}_{2}$ decreased by a rate $28.99 \%$, $\mathrm{CO}$ decreased by a rate of $26.24 \%, \mathrm{O}_{3}$ decreased by a rate of $11.62 \%$, and $\mathrm{PM}_{10}$ decreased by a rate of $30.04 \%$. These rates of percent reduction are essentially due to the reduction in traffic activities; concentrations of $\mathrm{NO}_{2}$ and $\mathrm{CO}$ are related mainly to the traffic activities, especially from diesel-fuel combustion, and to a low extent from gasoline transport vehicles, manufacturing industry, and power plants, especially in Umrah station (close to the industrial city and power plant northwest of Makkah).

Consequently, based on the confirmed case studies worldwide in different cities, we suggest a group of recommendations to enhance the air quality regime in Makkah city: (1) maximizing the public transportation via metro lines; (2) strengthening use of ultra-non-sulfuric fuel as advised by Euro 5 and 6; (3) encouragement and facilitating use of hybrid and electric vehicles; (4) firm control management of environmental topics such as industrial activities and power plants; and (5) expanding and increasing the green landscape around Makkah and its main entrances.

Acknowledgements The authors are grateful to the Deanship of Scientific Research at Umm Al-Qura University for encouraging and supporting the current research, in addition deep appreciation to PME (The General Presidency of Meteorology and Environment) for providing the air quality data. The authors are thankful to the editor and anonymous reviewers for their constructive comments and suggestions.

\section{Declarations}

Conflict of interest The authors approve that the current manuscript has no conflict of interest.

\section{References}

Abdou AEA (2014). Temperature Trend on Makkah, Saudi Arabia. Atmospheric and Climate Sciences, 2014

Abotalib AZ, Heggy E, Scabbia G, Mazzoni A (2019) Groundwater dynamics in fossil fractured carbonate aquifers in Eastern Arabian Peninsula: a preliminary investigation. J Hydrol 571:460-470

Ahmed E, Kim K-H, Shon Z-H, Song S-K (2015) Long-term trend of airborne particulate matter in Seoul, Korea from 2004 to 2013. Atmos Environ 101:125-133

Alizadeh-Choobari O, Bidokhti A, Ghafarian P, Najafi M (2016) Temporal and spatial variations of particulate matter and gaseous pollutants in the urban area of Tehran. Atmos Environ 141:443-453

Askariyeh MH, Arhami M (2013) Projecting emission reductions from prospective mobile sources policies by road link-based modelling. Int J Environ Pollut 53:87-106

Brook RD, Franklin B, Cascio W, Hong Y, Howard G, Lipsett M (2004) Air pollution and cardiovascular disease: a statement for healthcare professionals from the Expert Panel on Population and Prevention Science of the American Heart Association. Circulation 109:26552671

Chen H, Goldberg MS, Villeneuve PJ (2008) (2008) A systematic review of the relation between long-term exposure to ambient air pollution and chronic diseases. Rev Environ Health 23(4):243-297

Cyrys J, Eeftens M, Heinrich J, Ampe C, Armengaud A, Beelen R et al (2012) Variation of NO2 and NOx concentrations between and within 36 European study areas: results from the ESCAPE study. Atmos Environ 62:374-390

Dominici F, Peng RD, Bell ML, Pham L, McDermott A, Zeger SL, Samet JM (2006) Fine Particulate Air Pollution and Hospital Admission for Cardiovascular and Respiratory Diseases. JAMA. 295(10):11271134

El Bastawesy M, Al HK, Habeebullah T (2012) The hydrology of Wadi Ibrahim catchment in Makkah City, the Kingdom of Saudi Arabia: the interplay of urban development and flash flood hazards. Life Science Journal 2012:9(1)

Elkadiri R, Manche C, Sultan M, Al-Dousari A, Uddin S, Chouinard K, Abotalib AZ (2016) Development of a coupled spatiotemporal algal bloom model for coastal areas: a remote sensing and data miningbased approach. IEEE Journal of Selected Topics in Applied Earth Observations and Remote Sensing 9(11):5159-5171

Ezimand K, Kakroodi A (2019) Prediction and spatio-temporal analysis of ozone concentration in a metropolitan area. Ecol Indic 103:589598

Faridi S, Shamsipour M, Krzyzanowski M, Künzli N, Amini H, Azimi F, Malkawi M, Momeniha F, Gholampour A, Hassanvand MS, Naddafi K (2018) Long-term trends and health impact of $\mathrm{PM}_{2.5}$ and $\mathrm{O}_{3}$ in Tehran, Iran, 2006-2015. Environ Int 114:37-49

General Authority for Statistics (GAS) (2019) Hajj statistics 2019. KSA, Periodic Statistical Reports

Geng G, Zhanga Q, Martin RV, Donkelaar A, Huo H, Che H, Ling J, He $\mathrm{K}$ (2015) Estimating long-term $\mathrm{PM}_{2.5}$ concentrations in China using satellite-based aerosol optical depth and a chemical transport model. Remote Sens Environ 166:262-270. https://doi.org/10.1016/j.rse. 2015.05.016

Greenwood WR, Hdley DG, Anderson RE, Fleck RJ, Shmidit DL (1976) Late proterozoic cratonization in S.W. Saudi Arabia. Philosophical Transaction of the Royal Society of London, VA 280:3-38

Habeebullah TM (2013a) An analysis of air pollution in Makkah - a view point of source identification. EnvironAsia 6:11-17

Habeebullah TM (2013b) Health impacts of PM10 using AirQ2.2.3 model in Makkah. Aust J Basic Appl Sci 9:259-268

Heger M and Sarraf M (2018). Air pollution in Tehran: health costs, sources, and policies, environment and natural resources global practice discussion paper, The World Bank, April 2018 
Henschel S, Le Tertre A, Atkinson RW, Querol X, Pandolfi M, Zeka A, Haluza D, Analitis A, Katsouyanni K, Bouland C, Pascal M, Medina S, Goodman PG (2015) Trends of nitrogen oxides in ambient air in nine European cities between 1999 and 2010. Atmos Environ 117: 234-241

Hosseini V, Shahbazi H (2016) Urban air pollution in Iran. Iran Stud 49(6):1029-1046

Hu J, Wang Y, Ying Q, Zhang H (2014) Spatial and temporal variability of $\mathrm{PM}_{2.5}$ and $\mathrm{PM}_{10}$ over the North China Plain and the Yangtze River Delta, China. Atmos Environ 95:598-609

Mahato S, Pal S, Ghosh KG (2020) Effect of lockdown amid COVID-19 pandemic on air quality of the Megacity Delhi, India. Sci Total Environ 730:139086. https://doi.org/10.1016/j.scitotenv.2020. 139086

MoH (Saudi Ministry of Health) (2020): Periodic Reports and Guidelines for facing COVID-19 Pandemic.

Munir S, Habeebullah TM (2018) Vehicular emissions on main roads in Makkah, Saudi Arabia, a dispersion modelling study. Arab J Geosci 11:531

Munir S, Habeebullah TM, Seroji AR, Gabr SS, Mohammed AMF, Morsy EA (2013a) Quantifying temporal trends of atmospheric pollutants in Makkah (1997-2012). Atmos Environ 77:647-655

Munir S, Habeebullah TM, Seroji AR, Morsy EA, Mohammed AMF, Saud WA, Abdou AEA, Awad AH (2013b) Modeling particulate matter concentrations in Makkah, applying a statistical modeling approach. Aerosol Air Qual Res 13:901-910

Munir S, Habeebullah TM, Morsy EA, Mohammed AM (2018) The effect of tree plantations on moderating air temperature in Arafat, Makkah for the period 2002-2016. Journal of King Abdulaziz University 27(2):63-72

Nakada LYK, Urban RC (2020) COVID-19 Pandemic: impacts on the air quality during the partial lockdown in São Paulo State, Brazil. Sci Total Environ 730:139087. https://doi.org/10.1016/j.scitotenv.2020. 139087

Othman A, Abotalib AZ (2019) Land subsidence triggered by groundwater withdrawal under hyper-arid conditions: case study from Central Saudi Arabia. Environ Earth Sci 78(7):243

Othman A, Shaaban F, Abotalib AZ, El-Saoud WA, Gabr SS, Habeebullah T, Hegazy D (2020). Hazard assessment of rockfalls in mountainous urban areas, Western Saudi Arabia. Arabian Journal for Science and Engineering, 1-15

Pope CA III (2007) Mortality effects of longer term exposures to fine particulate air pollution: review of recent epidemiological evidence. Inhal Toxicol 19(sup1):33-38

Seifi M, Niazi S, Johnson G, Nodehi V, Yunesian M (2019) Exposure to ambient air pollution and risk of childhood cancers: a populationbased study in Tehran, Iran. Sci Total Environ 646:105-110

Selvam S, Muthukumar P, Venkatramanan S, Roy PD, Manikanda BK, Jesuraja K (2020) SARS-CoV-2 pandemic lockdown: effects on air quality in the industrialized Gujarat State of India. Sci Total Environ $737: 140391$
Seroji AR (2011) Particulates in the atmosphere of Makkah and Mina Valley during the Ramadan and Hajj seasons of 2004 and 2005. In: Brebbia CA, Longhurst JWS, Popov V (eds) Air pollution XIX. Wessex Institute of Technology, Ashurst, UK

Song C, He J, Wu L, Jin T, Chen X, Li R, Ren P, Zhang L, Mao H (2017) Health burden attributable to ambient $\mathrm{PM}_{2.5}$ in China. Environ Pollut 223:575-586

Squizzato S, Masiol M, Rich DQ, Hopke PK (2018) $\mathrm{PM}_{2.5}$ and gaseous pollutants in New York State during 2005-2016: spatial variability, temporal trends, and economic influences. Atmos Environ 183:209224

Taghvaee S, Sowlat MH, Mousavi A, Hassanvand MS, Yunesian M, Naddafi K, Sioutas C (2018a) Source apportionment of ambient $\mathrm{PM}_{2.5}$ in two locations in central tehran using the positive matrix factorization (PMF) model. Sci Total Environ 628:672-686

Taghvaee S, Sowlat MH, Hassanvand MS, Yunesian M, Naddafi K, Sioutas C (2018b) Source-specific lung cancer risk assessment of ambient $\mathrm{PM}_{2.5}$-bound polycyclic aromatic hydrocarbons (PAHs) in central Tehran. Environ Int 120:321-332

The Ministry of Ecology and Environment of the People's Republic of China (MEE). China Vehicle Environmental Management Annual Report (2016). http://www.mee.gov.cn/home/jrtt_1/201606/ t20160602 353154.shtml

The Ministry of Ecology and Environment of the People's Republic of China (MEE). China Vehicle Environmental Management Annual Report (2017). Available at, http://www.mee.gov.cn/gkml/sthjbgw/ qt/201706/t20170603_415265.htm. Accessed 3th June 2017

The Ministry of Ecology and Environment of the People's Republic of China (MEE). China Vehicle Environmental Management Annual Report (2018). http://www.mee.gov.cn/gkml/sthjbgw/qt/201806/ t20180601_442293.htm

Tobias A, Carnerero C, Reche C, Massagué J, Via M, Minguillón MC, Alastuey A, Querol X (2020) Changes in air quality during the lockdown in Barcelona (Spain) one month into the SARS-CoV-2 epidemic. Sci Total Environ 726:1-4. https://doi.org/10.1016/j. scitotenv.2020.138540

Tonse SR, Brown NJ, Harley RA, Jin LA (2008) Process-analysis based study of the ozone weekend effect. Atmos Environ 42:7728-7736

Xu P, Zhang J, Ji D, Liu Z, Tang G, Hu B, Jiang C, Wang Y (2016) Evaluating the effects of springtime dust storms over Beijing and the associated characteristics of sub-micron aerosol. Aerosol Air Qual Res 2017 17:680-692. https://doi.org/10.4209/aaqr.2016.05.0195

Zambrano-Monserrate MA, Ruano MA, Sanchez-Alcalde L (2020) Indirect effects of COVID-19 on the environment. Sci Total Environ 728:138813. https://doi.org/10.1016/j.scitotenv.2020. 138813

Zuberi MJS, Torkmahalleh MA, Ali SH (2015) A comparative study of biomass resources utilization for power generation and transportation in Pakistan. Int J Hydrog Energy 40(34):11154-11160 